\title{
Saudi Arabia and the travelling scientist
}

ONLY in the past week has the outside world come to hear of the particularly savage public executions in Saudi Arabia last November of a princess and her husband for, apparently, contracting a marriage contrary to royal decree. At least the couple were spared being stoned to death-a fate which befell three men in Saudi Arabia last year after they had been found guilty of sexual offences. The Islamic code of justice has harsh things in store for sexual transgressors, and Saudi Arabia is not, of course, the only country that operates such a code.

But why is this any special concern of the readers of Nature? Certainly we should be exercised when states interfere with the elementary human rights of scientists or when they tamper with the means of scholarly communication. But is this recent matter, however barbarous and seemingly unjust by our different moral and legal standards, any cause for scientists to take special interest in?

The answer is yes. Saudi Arabia is in the throes of a mighty transition, often described as a leap from the Middle Ages to the atomic era. Science, technology and medicine are playing an enormous role in effecting this change, and higher education-non-existent before 1947-is now open to several thousand students each year. What is more, Saudi Arabian interests are not exclusively in applied science; there has been talk of a particle accelerator and rather more than talk about a major telescope. All of this has meant an increasing flow of Western scientists into the country to teach, collaborate and advise.

Such scientists have an easy and relaxed access to the Saudi intellectual community - easier, probably, than that of any other group, as they are not there specifically to sell equipment, buy oil or represent the delicately balanced interests of their home country. They thus have an excellent opportunity for quiet and honest conversations with hosts about the way that Saudi Arabia looks from the outside world and how decades of impressive achievements can count for little if there are not comparable developments towards at least the elements of a society that is humane and just.

Much informed opinion in Saudi Arabia would probably already concur with all this, but its hand would be immeasurably strengthened in pressing for change were the message to be repeated from the outside as often as possible. And there are several other countries where, equally, the travelling scientist can be a power for good in this way. Maybe we underestimate the influence that the global scientific community could have with its liberal attitudes and ease of access to people of influence.

\section{Medical education and biomedical research: uneasy equilibrium}

George A. Silver, Professor of Public Medicine in the School of Medicine, Yale University, argues that medical education should be separated from research if the best doctors and research workers are to be produced.

Among the casualties of the upheavals of the 1960 s, one of the most far-reaching has been the dissipation of unlimited faith in the benevolence of science and the efficacy of progress along with a loss of confidence in social institutions generally. Biomedical research and medical education have both suffered the consequences, although in different ways and to a different extent. There is dissatisfaction with the medical care system, a dawning recognition that not all diseases may be curable and scepticism of the motives of both medical educators and researchers.

A medical school dean writes (Sherman M. Mellinkoff Johns Hopkins Med. Jour. 141, 167; 1977): “Triumphs of the biomedical sciences have burgeoned exponentially. Nevertheless there sometimes seems to be a miasma of something between apprehension and gloom over the American medical schools of this decade. Seldom has medical education been subjected to so much criticism, ranging from valid to vicious, from thoughtless to mindless. It is as though success had earned no laurels but a handful of nettles." And he attaches a litany of the public and popular complaints, among which the outstanding are “... that medical students are deliberately selected or molded to be overly scientific and lacking in altruism" and that the schools ". . . pay too much attention to abstruse problems and neglect common ailments ..." both of which he considers false.
In searching for the culprit, if there is any, the questioning seems to centre on this intertwined relationship, the apparently indissoluble bond, between biomedical research and medical education. A measure of obloquy has in recent years fallen on Abraham Flexner, the educator whose report on medical education in the United States (Medical Education in the United States and Canada, Carnegie Foundation for the Advancement of Teaching, NY (1910)) is considered the platform from which modern medical education was launched. Although Flexner epitomised a tide then running and so gave his name to the course of events already in train, he should only bear responsibility for recognising the trend and helping establish a rational base for medical practice. $\mathrm{He}$ did propose the university as the locus for medical education and medical research as an important associated activity.

But 'research' in the early years of this century was not the research we know today. One must visualise Sir William Osler, observing patiently and critically, recording the natural history, symptomatology and autopsy evidence of disease as the prototype of the investigator of that day. There was only modest and inexpensive equipment in the laboratory for examination and study. In short, 'research' was essentially clinical study in a scientific style.

Now that we have a multimillion-multibillion dollar research industry fastened upon the medical education process throughout the academic world, we begin to have second thoughts. Examination of the medical research and medical education budgets for 1975 , shows that while $\$ 800$ million went specifically for research, only $\$ 368$ million went into teaching and training in the academic institutions. Total budgets for the medical schools were twice this amount, including many other kinds of payments, but 